\title{
Investigation on Iranian Translators' Awareness of Semantic Prosody
}

\section{Negin Yazdani Motlagh ${ }^{* 1}$, Atefesadat Mirsaeedi ${ }^{1}$}

${ }^{1}$ Foreign Language Department, Islamic Azad University of Isfahan (Khorasgan) Branch, Isfahan, Iran

\begin{tabular}{llllll}
\hline Received: 12.10 .2021 & $\bullet$ & Accepted: 05.01.2022 & $\bullet$ & Published: 03.03.2022 & • Final Version: 05.03.2022 \\
\hline
\end{tabular}

\begin{abstract}
In recent years, with the advent of technology and increasing international communication, translation became more important than before especially translation of politics, great novels, books, and news so researchers have to determine challenging issues in translating and communication process in order to have higher quality in translation and communication. One of these challenges is semantic prosody that first introduced by Sinclair (1987) as a special tendency of words to occur in special semantic prosody. This research is based on both qualitative with search analysis design and quantitative by drafting a questioner with 56 participants from the Islamic Azad University of Isfahan (khorasgan) branch. As a result, the charts show that despite the importance of knowing semantic prosody there is still a lack of knowledge in semantic prosody among Persian translators. There should be a special dictionary for demonstrating semantic prosody of words and in the translation training, there should be more attention on translation challenges.
\end{abstract}

Keywords: Semantic Prosody, Corpus Study, Translation Challenge, linguistic problem, corpora

\section{Introduction}

Al-Sofi et al (2014) mentioned Semantic prosodies are lexical items that have a tendency to occur in a special semantic environment. The semantic environment that words occur in could be positive or negative or neutral. Using words with correct semantic prosody gives the text or speech harmony and cohesion because it keeps the discourse together. Sinclair (2003) noted that semantic prosody conveys its pragmatic meaning and attitudinal meaning. The importance of knowing the semantic prosody of words is that Sometimes for having humor, irony, or metaphor the semantic prosody occurs in the opposite semantic environment so the meaning of context would change completely. Native people know the concept of semantic prosody unconsciously but it is important for the translators who want to connect two societies with different cultures, know the lexical items and their tendency exactly since it can affect judging sentences (Cohen et al., 2001). The fact is that semantic prosody is not paying attention as an important issue in translation especially in Persian (Farsi, also known as the Persian Language, is the most widely spoken member of the Iranian branch of the Indo-Iranian languages, a subfamily of the Indo-European languages.) Translators may not know even the concept meaning of this issue. In this research, the aim is to show that the Persian translators are not aware of the semantic prosody or is they know is completely unconscious and based on their past information. This article by drafting a questioner with 16 questions in both Persian and English language examined the knowledge of translators and shows that how it would affect the final meaning concept and judgment of receivers. Over the past decades, semantic prosody and its

* Correspondent author, Negin Yazdani Motlagh: neginyazdani.motlagh@gmail.com 
definition have attracted many research interests but there is no research that shows the difficulty of semantic prosody and lack of knowledge in Persian translators.

\section{2-Literature Review}

Semantic prosody could be a concept that has been the attention of interest since the primary project that has been done by Sinclair in 1987 then semantic prosody gains plenty of attention. Laow's definition of semantic prosody was a "consistent aura of meaning with which a form is imbued by it collocates". The 'father' of the term semantic prosody is Bill Louw who introduced the term to the general public in 1993, he also introduced the term semantic preference to the general public in 1993. Bublitz defined semantic prosody as "a special halo, profile or environment that words have a tendency to occur in Bublitz (1996: 9). This environment may be positive which causes a "positive semantic prosody". For example, the word "finish" has positive semantic prosody and mostly occurs in positive environments as in the sentence "the celebration finished". On the other hand, sometimes the environment is negative, so it causes a "negative semantic prosody". For instance, the word "end" has negative semantic prosody and it mostly occurs in negative sentences like "the war has ended". In translation, choosing an appropriate equivalent is essential to convey the right message from source-text to target-text, and one of the issues that may have a determinative role in appropriate equivalent choice is the semantic prosody. According to the article from Ahmadian et al. (2011), despite the importance of semantic prosody, there is still not enough attention in the teaching of semantic prosody in both fields of English language acquisition and translator training. As mentioned in Zhang (2009) ignorance of semantic prosody is common among ESL/EFL learners (cited in weir, 2006; Xiao \& McEnery, 2006). Also, as mentioned by weir, (2006), Xiao \& McEnery, (2006) inappropriate word choice comes from the ignorance of semantic prosody. Hence, when there is no training in translators' courses about semantic prosody the translator's knowledge of semantic prosody is not enough too. Ignoring semantic prosody causes a cliched, comic, or ironic effect in the target text and to this point sometimes semantic prosody can change the context or meaning of words completely. The findings of the studies showed that the translator's knowledge of semantic prosody in the context was almost average. However, this extent is not enough; because SP has a great impact on the appropriate selection of equivalents in translation so on conveying the right message from ST to TT, translators need to be more sensitized to the SP behaviors of words. In words selection, there is a wide range of features that may affect the meaning of the word and one should pay attention to them. While some of these features are not noted in the official dictionaries but they are very important and effective in conveying the meaning. Researches have shown that in recent decades semantic prosody aspect of words comes into view as a significant point of meaning in the words that can change the meaning of the sentence. In the last few decades due to the development of technology and computer science, many studies such as Bagaric, (2013) studies have been done in relation to semantic prosody and utilizing specialized programs and million-word corpora. In research that has been done by Lain McGee, seven lexical items with both negative semantic prosody and positive semantic prosody have been selected from corpus linguists' sites. Two graduate and undergraduate students of English translation studies that were native in the Arab language were selected and besides these two groups, one group with native English language was also chosen. For each of the seven items, the participants were asked to write to a maximum of three e example sentences. The result has shown that the first group of participants that they were undergraduate students for Group 1, only four of the seven items elicited sufficient data for analysis in group two only five sentences were considerable but in group three that they were English native speakers in all sentences, the semantic prosody was considered. In research that has been done by Mashaei Al Rajhi (2019) four words with different semantic prosody were chosen and asked the 
nonnative student to make a sentence with them and the study was based on the Zhang, claim in 2009 that said EFL learners often make semantic prosodic errors in communication as they rarely notice the semantic prosody of the items they learn. The participants of this study were students of applied linguistic They were asked to write a descriptive essay in class using the four words among 'completely, utterly, entirely, fully, perfectly, totally, absolutely. The semantic prosody of these words was identified before with the help of corpus sites. The data analysis of the students' essays shows that 'completely' was the most frequently used in the sample and this is because of the fact that students were aware of the semantic prosody of this word. The result indicates that most of the students in the sample felt more comfortable with using 'completely' in their essays. Benna (2014) have been done research Towards a Semantic Prosodies Approach in the Study of Irony he mentioned by the advent of large corpora such as the LOB, Brown and etc., it is possible for readers to perceive consistencies in the influence of collocation on the behavior of particular linguistic for. He analyzed the semantic prosody of words in the book Hemingway's A Farewell to Arms and their irony and hidden meaning. The study was based on corpus design in BNC corpora. Finally, the result indicated that the semantic prosody it is worth noting that for thousands of years semantic prosodies remained hidden from our perception. Base on research that has been done in 2021 by Natali Kubler between French and English languages results demonstrated that semantic prosody does not have a univocal match between two languages. Moreover, the study indicated the need for corpus data over intuition to understand the fluctuation of semantic prosody between general language and languages for specific purposes. Bill Louw (2010) expressed when there is a distance between the expected word and the combination of words proposed by the author hence the result is irony. Also, the poets in this way try to create an effect he analyzed the word "fine" and claimed that this word normally expresses positive semantic prosody like "fine actress" but this prosody can become an irony like a sentence that Obama used to describe Sara Palin: "obviously she is - a fine- mother- up-and-coming public servant". Hauser \& Schwarz, (2016) investigated among corpora sites and claimed that some words have valanced meaning, for instance, the word "right" and "evil" clearly have positive and negative valanced meaning and this negativity and positivity is in their own definition. They said that valanced meaning has no nonvalanced synonyms and valance is at the core of what those words mean. In contrast, semantic prosody often has lacked valance meaning in their own definition in this situation the nonnative speaker of that language cannot understand whether the word is positive or negative. Words with semantic prosody often have synonyms that can be substituted for the word and still have the sentence mean the same thing, for example, the word "bent on" doesn't have any negativity in its definition and nonnative English speaker may not know that "bent on" has negative semantic prosody. This research is an attempt to show the importance of semantic prosody and while semantic prosody is very important and effective in translation studies but the translator is not aware of this linguistic phenomenon and this can decrease the quality of translation and also may change the sentence and its notion from one language to another. While semantic prosody is a new subject in linguistic and corpus base studies but due to the importance of this subject, there is a wide range of studies in this subject and the significant point of this research from other is that this research tries to demonstrate search among Persian translators and compare English to the Persian.

\section{Methodology of the Study}

This research is conducted based on mixed methods of research. The qualitative part of the questioner will determine that selecting two synonym words with different semantic prosody is problematic for the translator. Synonym pairs selected from the Oxford dictionary and their frequency estimates in "COCA, COHA" then based on "Cochran formula" a representative number of all calculate. Finally, the special semantic prosody for each word will be recognized and used in the questionnaire. 
The designed questionnaire has 16 multiple-choice questions and will examine the translator's awareness of semantic prosody. It is online and was designed at the "Google Form" utility website. To this end, 56 graduated/undergraduate students of the translation studies will be selected randomly as the participants. The translators will be selected from the "Islamic Azad University of Isfahan (Khorasgan) branch".

\subsection{Research Setting}

This study was done in Isfahan Islamic Azad University (Khorasgan) Branch, located in the eastern zone of Isfahan.

56 Students who were graduated / undergraduates from the English translator training program were Randomly selected as the case study of this research.

\subsection{Participants of the Study}

This study was conducted at Isfahan (Khorasgan) University, in the east of Isfahan, Iran, in the academic year 2020-2021 and during the second semester, focusing on semantic prosody as a linguistic challenge in translation.

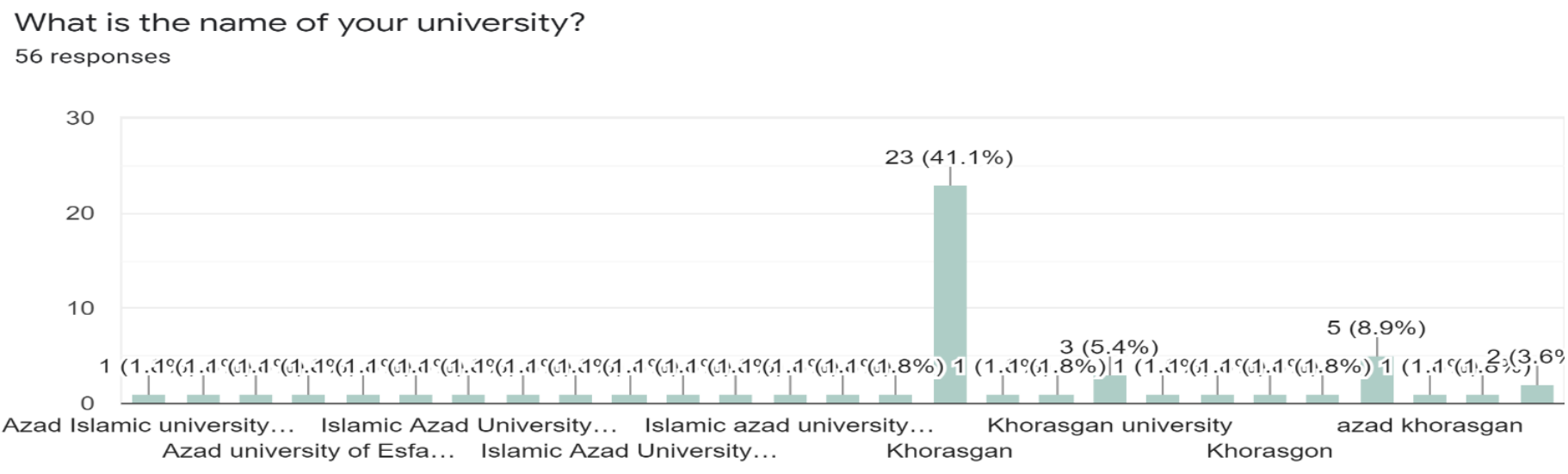

Figure. 1. participants' university

56 students were selected as participants of this study in the first step to show the lack of awareness about semantic prosody among translators. The selected participants were graduated/undergraduate students because they have completed their training and are ready to start as translators in industries.

As it is shown in figure 3.2., the graduate/non-graduate students were from the Islamic Azad University of Isfahan (Khorasgan) branch. The students at Isfahan (Khorasgan) University were selected as a sample for Iranian translators who were accessible. Hence, they preserve the purpose of this study. 
How old are you?

56 responses

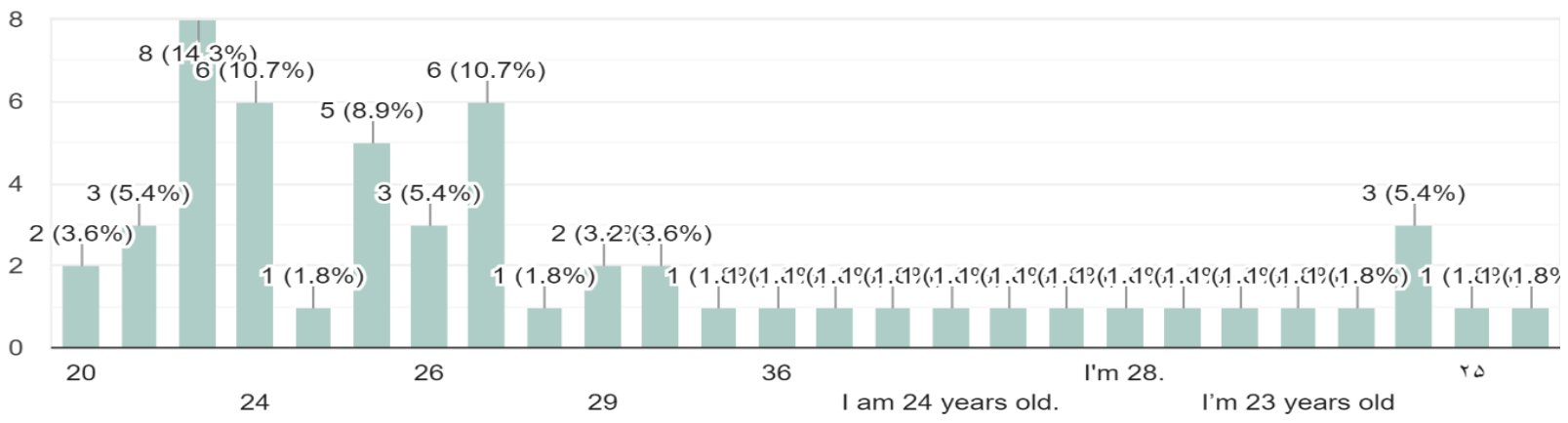

Figure 2. Age of participants

In this study, age was not a matter because age does not affect the translator's awareness of semantic prosody.

It is obvious in figure.3.2 that participants were up to 20 years old because they are graduated and undergraduate students.

What is your gender?

56 responses

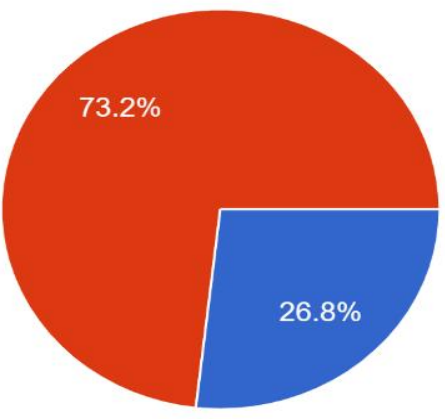

Male

Female

Figure 3. participants' gender

It is clear in figure.3.3. that participants were both male and female because gender does not affect the awareness of semantic prosody. This investigation gender of participants does not affect the translator awareness of semantic prosody. 
figure 4. participants' field of study

What is your major?

56 responses

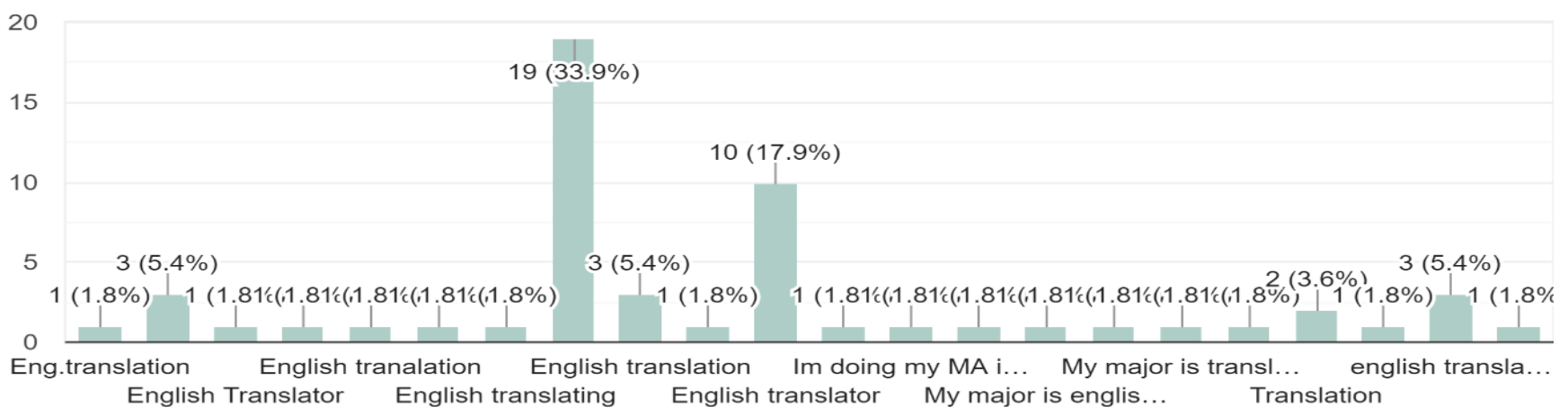

All of the participants were graduated and undergraduate students in English translator training, which is shown in figure 3.4. This is very important because major participants were the most crucial factor because the purpose of the study is to investigate the translator's awareness of semantic prosody.

This research study aimed to examine awareness of semantic prosody and indicate that even though translators do not have enough knowledge of semantic prosody, this is an essential issue in the linguistic and translation field.

\subsection{Research Instruments}

A range of quantitative and qualitative instruments was employed in this research to collect data. An official dictionary which is very important to estimate semantic prosody of words that in this research, Oxford dictionary was selected. An online questionnaire consists of fifteen questions in the "google from" and was checked to determine the translator awareness of semantic prosody. The required Corpus websites were "COCA" and "COHA" which are the largest corpora sites and include millions of real examples during years. Since the examples in the corpora sites are many, using the "COCHRAN" formula was recommended to estimate the represented number of examples. In the quantitative part of the study, the awareness of the translators in semantic prosody and its knowledge were gathered and checked.

\subsection{Questionnaire}

A questionnaire consisting of 15 items and was administered to determine Translators' awareness of semantic prosody. To this aim, the questioner was designed in multiple-choice with synonym words which have different semantic prosody. First, the synonym words have been chosen in the Oxford dictionary. Each question in questioner has been completed even with Persian translation of the English form or without. The questioner formed in "Google form" and due to the Covid-19 situation, the process of answering was online.

\subsection{Data Collection Procedure}

In this research, four ways of collecting data were used:

Corpus analysis design along with checking and recognizing semantic prosody of synonym words with different semantic prosody and their frequency in "COCA, COHA". Semantic prosody is among those researches which are searchable through corpora sites. Corpora sites contain a wide range of real-life examples of sentences in the English language since past decades. The mentioned corpora 
sites have been chosen because they are more complete and up to date than other corpora sites such as "Helsinki".

Calculating the represented number of each word during the math process of "Cochran formula". With the help of "Cochran's formula", it is possible to determine the representative number for each word. The mentioned formula has been chosen because it can facilitate the analysis among millions of examples. The Cochran formula process is as below:

Cochran's formula: $n=\frac{N z^{2} p q}{N d^{2}+z^{2} p q}$

$\mathrm{z}=1.96, \mathrm{p}=\mathrm{q}=0.5, \quad \mathrm{~d}=0.05, \quad \mathrm{~N}=$ variables

Making a questioner on the "Google Form" website with a random selection of participants from graduated/non-graduated translation students of the Islamic Azad University (Khorasgan) branch. The "google form" was selected because it is a website facility that helped the researcher in the Covid-19 situation.

1- Searching among official books and articles related to semantic prosody and linguistic problems in translation such as "Oxford" and "Longman" dictionaries are the most famous dictionaries in English. The most helpful book that could fulfill this research's needs was "semantic prosody" written by Dominic Stewart.

\subsection{Characterization of the Target Group}

All of the participants have been randomly chosen from graduated/undergraduated students of English language translation studies in the Islamic Azad University of Isfahan (Khorasgan) branch. The age and gender of the participants were not a matter of fact in this study because they are not effective in the result of this study.

\subsection{Data Analysis Procedure}

A number of near-synonym pairs with different semantic prosody were selected from "COCA, COHA" databases. Then with the help of the "Cochran formula", the semantic prosody of the chosen word recognized and used in the questioner. 56 participants were randomly chosen from the graduate/non graduated translator students of the Islamic Azad University of Isfahan (Khorasgan) branch. The age of the participants is not relevant because it does not affect the result of the study. Findings analyzed based on Sinclair's (1996) hypothesis of SP as well as Stubbs (1995) and Partington's (1998) model of SP classification analyze as below.

1- By analyzing the corpus sites highlighted the importance of semantic prosody and found some synonym pairs with the same semantic prosody.

2- Scattered repeated data and nonrelated majors in order to have more valid and reliable research.

3- Calculated the whole number of people who participated in this study base on the needs of the study.

4- Estimated selection percent of each option.

5- Compared between correct and incorrect answers.

6- Examined semantic prosody's awareness among translators.

7- Identified the sources of lack of knowledge among translators

\subsection{Descriptive Analysis of the Questionnaire}


As mentioned before in the process of the questioner, there were questions in the forms that each question contained synonym words with different semantic prosody to measure to what extent does the Persian translation know the semantic prosody background knowledge and the result of each question is be estimated as below:

In the first question, the comparison was among Persian and English translations of the verb " "دادن" which does not have any specific semantic prosody in the Persian language. However, the English synonyms for this verb in English are "happen, occur, come, arise" all of these synonyms have specific semantic prosody in English corpora sites.

The subject of the Persian sentence is" انفاق خوب " and in English “something good" so translators must choose a word with positive semantic prosody but as the responses indicate around 8.9 percent of participants were aware of the semantic prosody of the verb "come" which is positive.

Figure.5

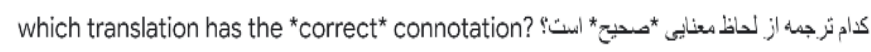

56 responses
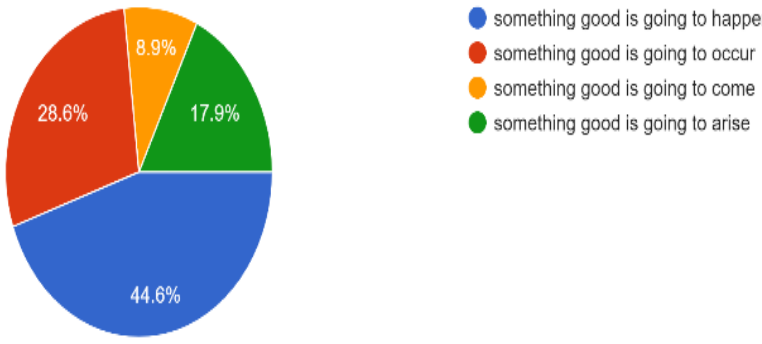

In the above question, four synonym words in English compared. although these words in English are synonyms, they have different semantic prosody among these words. The only word that have positive semantic prosody is "come". The participants had to guess which words are the best option in this positive collocation. Around 8 percent of participants choose the correct sentence. Others did not know that only the verb "come" has positive semantic prosody and is the correct answer among these words.

\section{Figure.6}

كام ترجمه از لحاظ معنايى *اشتباه* است؟ ? which translation *doesn't* have a correct connotation 56 responses

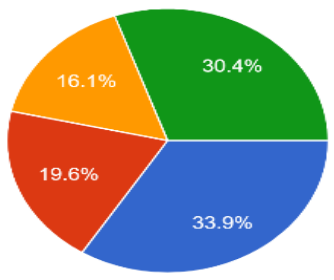

your try is symptomatic of your

hardworking personality

your try is symbol your hardworking personality

your try is sample of your hardworking

personality

your try shows your hardworking

personality
In the second question, the comparison

was again

among Persian and English translations of the same word " نشانه "which by with the help of English corpora sites and official dictionaries the synonym for These words were selected as following "symptomatic, symbol, sample, shows. the object of the sentence had a positive meaning and "try" and in Persian " "تلاشso the chosen word must have positive semantic prosody but in all of the choices the verb has negative semantic prosody and only the last choice has positive semantic prosody and must be a correct answer but as it is clear below only about $30 \%$ of students were aware of this 
difference among verbs and other $70 \%$ did not pay attention to semantic prosody of the verbs and its subject.

Figure.7

كhich translation *doesn't* have the correct connotation? كدام ترجمه از لحاظ معنايى *اشتباه* است؟

56 responses

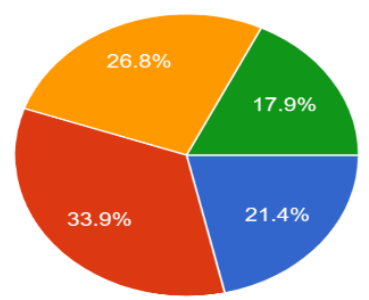

your speech causes a problem

your speech result in a problem

your speech happens to a problem

your speech builds up a problem

In the third question, the participants were asked to choose incorrect equivalence for the Persian sentence of "حرف تو باعث مشكل شد"or in another meaning the incorrect verb for the word "problem".

In all of the choices the verbs have negative semantic prosody "cause, happen, result in" the only incorrect form is the verb "build up" which has positive semantic prosody. Around 18\% of students were aware of the semantic prosody of the verb build up and they just notice the most repeated sentence in their environment.

\section{Figure.8}

which sentence *doesn't* have the correct connotation?

56 responses

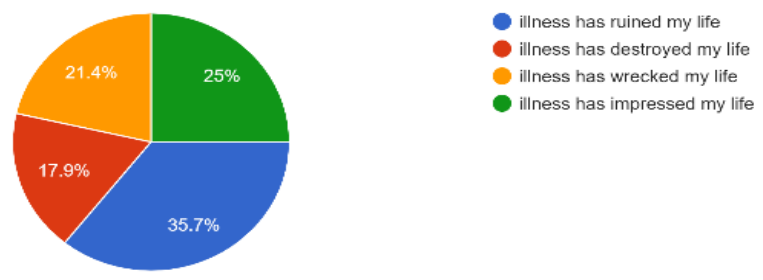

In the fourth question, the participants were asked to choose a wrong answer. The comparison was among different verbs for the subject of "Illness". The participants had to select a verb with negative semantic prosody among four verbs of "ruined, destroyed, wrecked, impressed".

The correct answer is the verb impress because it has positive semantic prosody and it cannot be matched with "illness" which has a negative meaning. However, just around 25 percent of participants selected a correct answer. 


\section{Figure.9}

5 in which sentence the word (incurred) is connotative *wrong*?

56 responses
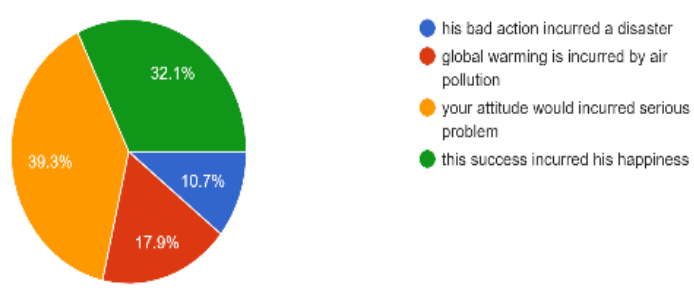

In the fifth question participants had to choose the wrong object for the verb "Incurred"

Which has negative semantic prosody. In all of the choices the subject has positive meaning but in "Success". 32 percent of the participants answered correctly but still, $32 \%$ is not a good presentation of the whole.

\section{Figure.10}

in which sentence the word (happen) is connotative *wrong ${ }^{\star}$ ?

56 responses

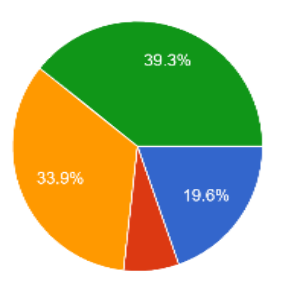

conversation.

Regarding the corpora sites the verb "Happen" has negative semantic prosody. In this question, all of the sentences have a negative meaning except the last option which the object is "Satisfied" as in wrong the option we are considering. Around 40 percent answered correctly.

Figure.11

in which sentence the word (utterly) is connotatively *wrong*?

56 responses

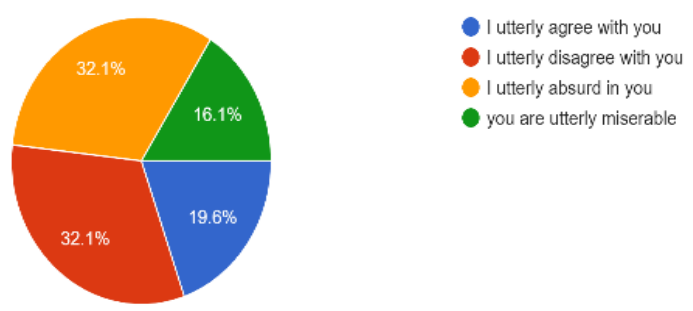

The question focused on the semantic prosody awareness of the verb "Happen" which has high usage in our everyday 


\section{Figure.12}
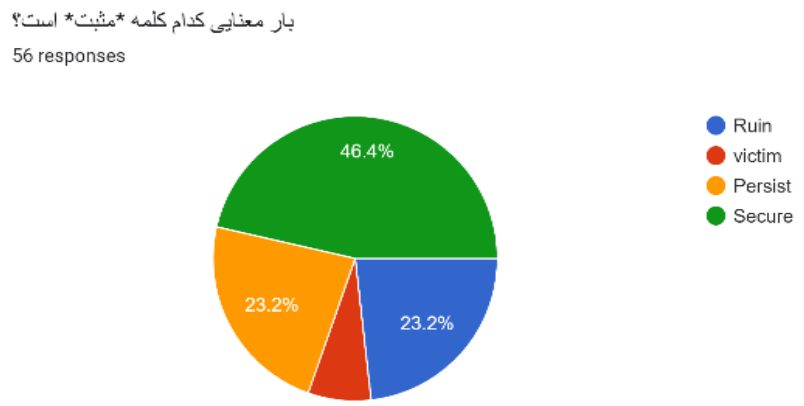

In the eighth question participants were asked to choose a word with positive semantic prosody among the words "Ruin, Victim, Persist, Secure". All of these words have negative semantic prosody but "Secure" and around 46 percent of participants were aware of the semantic prosody of this word.

which word has a *negative* meaning?

Figure.13

56 responses

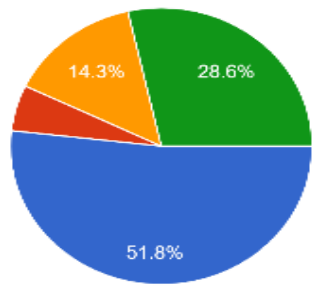

Provide

Impressive

Arise

In the ninth question, participants were asked to choose a word with negative semantic prosody and the words included "Entirely, Provide, Impressive, Arise". As it is clear all of them have positive semantic prosody except "arise" and only $30 \%$ of participants answered correctly.

Figure.14

which word has a *positive* meaning?

56 responses
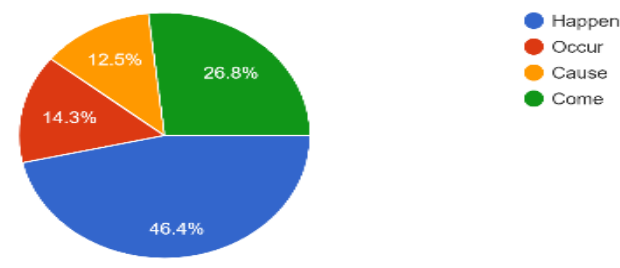

In the tenth question, the participants had to choose positive semantic prosody among "Happen, Occur, Couse, Come". All of the mentioned words have negative semantic prosody except for the word "come". About 30 percent of participants answered correctly. 
Figure.15

which word has a *negative* meaning?

56 responses

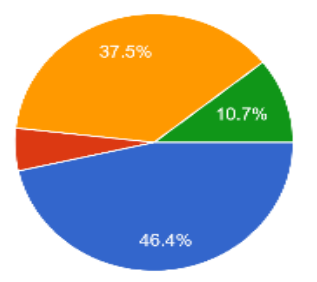

Tripe

Travel

Immigration

Joumey

In, the eleventh question the participants had to a word with negative semantic prosody.

All of the words "Tripe, Travel, Journey" have positive semantic prosody. However, the word "immigration" had negative semantic prosody and was the answer to our question and around 38 percent of participants answered correctly.

Figure.16

which word has a *positive* meaning?

56 responses

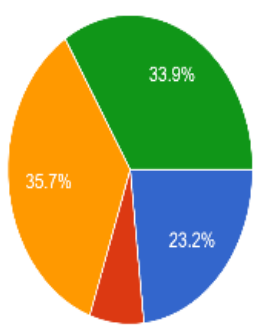

In, the twelfth question the participants were asked to choose a word with positive semantic prosody among "Result In, End Up, Provide, Lose". All of the above words have negative semantic prosody except for the word "Provide" and around 37 percent of students were aware of the answer.

Figure.17

which sentence has a * positive* meaning?

56 responses

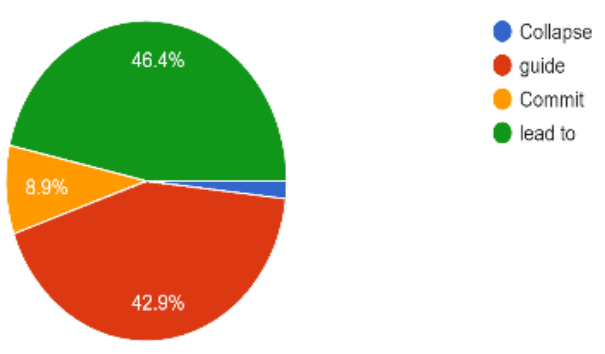


In the thirteenth question the participants had to choose a word with positive semantic prosody among the below words: "Collapse, Guide, Commit, Lead To" all of the mentioned words have negative semantic prosody except "Lead to" and around 46 percent of participants were aware of the correct answer.

Figure.18

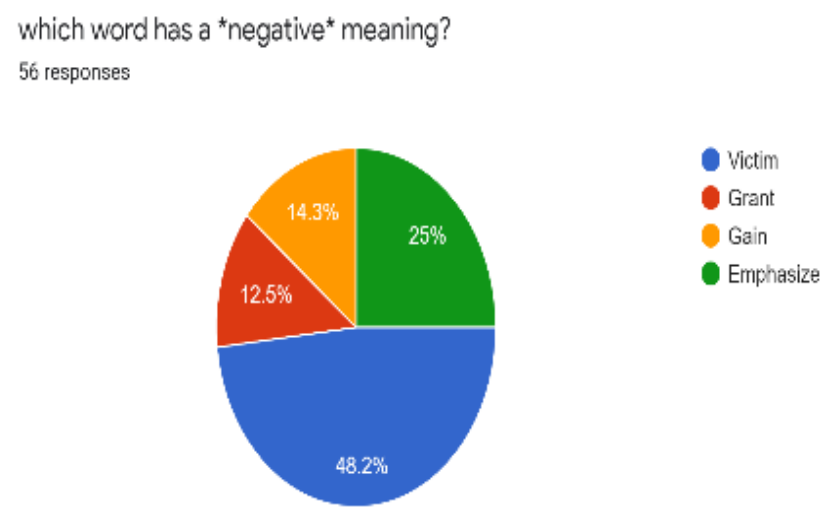

In the fourteenth question, the participants had to pick up a word with negative semantic prosody. all of the chosen words had positive semantic prosody "Emphasize, Grant, Gain" but the last option "Victim" has negative semantic prosody and 48 percent of the students knew this fact.

Figure.19

which sentence has the *correct* connotation?

which sentence has the ${ }^{*}$ correct $^{\star}$ connotation?

56 responses

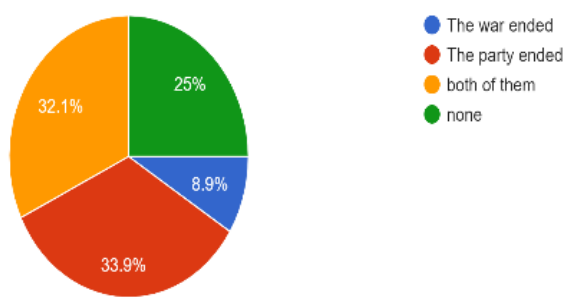

Figure.20

In the last two questions, the struggle was among semantic prosody of two synonym words "End, Finish" and "Start, Begin".

As it is clear in all corpora sites the two words "end, begin" have negative semantic prosody, and the two words "Finish, start" have positive semantic prosody. However, it is obvious in the two figures that only 35 percent of participants were aware of the semantic prosody of these two synonyms words. 


\subsection{Questioner result}

Due to the one-by-one analysis of questions in the questioner, the result indicates that more than half of the participants did not know any background knowledge of semantic prosody. Some of them before answering the question asked and needed more information about semantic prosody can also prove this. The total result proves the fact that there is no specific teaching on the semantic prosody and these kinds of linguistic differences which Couse a problem through translating process and this result is in the case that they are very important and effective in the process of translating and may completely change the meaning of the sentences. It can also have irreversible results in the political issues and their translation.

\section{5-Conclusion}

As can be seen in the charts above there is a lack of knowledge of semantic prosody among translators. This result is despite the fact that knowing this phenomenon is one of the important factors to convey meaning from source language to the target language in any genre and both written or spoken form. Correct usage of semantic prosody gives the text/speech harmony, cohesion and it keeps the discourse also somehow people use opposite environments for the words with special semantic prosody in order to have irony humor or metaphor and if the translations were not aware of this special tendency, he/she cannot convey the correct means of speaker or writer of the source language. For a better understanding and having a high quality of communication, there should be more attention to the field of translation training and teaching the semantic prosody of the words to future translators. The results show that there are some synonym words in the English language that while they have the same meaning but they have different semantic prosody and it can Couse a problem in the translation of Persian to English even written or spoken translation. For example, two words "start, begin" have both the same meaning and there is no difference in their dictionary meaning but in corpora sites, it is clear that the word "start" mostly has positive semantic prosody and use in a positive colocation.

\section{Reference}

[1] Bublitz, W. (1996). Semantic prosody and cohesive company: Somewhat predictable. Leuvense Bijdragen: Tijdschrift voor Germaanse Filologie, 85(1-2), 1-32

[2] Baker, P. (2010). Corpus methods in linguistics. In L. Litosseliti (ed.), Research methods in linguistics (pp. 93-113). London: Continuum

[3] Bastin, G. L., \& Bandia, P. F. (2006). Charting the future of translation history. In Charting the Future of Translation History. https://doi.org/10.2307/j.ctt1ckpfkh

[4] Benna, S. (2014). Towards a Semantic Prosodies Approach in the Study of Irony. Journal of advances in linguistics. https://doi.org/10.24297/jal.v5i1.2734

[5] Hauser, D. J., \& Schwarz, N. (2016). Semantic prosody and judgment. Journal of Experimental Psychology. General. https://doi.org/10.1037/xge0000178

[6] John Sinclair. (1992). Corpus, concordance, collocation. Oxford University Press. Lenguas Modernas.

[7] Louw, Bill. (2000). Contextual prosodic theory: Bring semantic prosodies to life. Words in Context: A Tribute to John Sinclair on his Retirement, ed. by Chris Heffer and Helen Sauntson, 48-94. English Language Research Discourse Analysis Monograph No. 18, CD-ROM. Birmingham: University of Birmingham.

[8] Louw W.E (1993). Irony in the text or insincerity in the writer? the diagnostic potential of semantic prosodies. In Baker, M., Francis G. and tognini-boneli, E., editors' text and technology: in honor of John Sinclair Amsterdam: John Benjamin, pp.157-179

[9] McGee, I. (2012). Should we teach semantic prosody awareness? RELC Journal. https://doi.org/10.1177/0033688212449485

[10] McEnery, T., Hardie, A. (2011). Corpus Linguistics: Method, Theory, and Practice. Cambridge: Cambridge 
[11] McEnery, Tony, and Andrew Hardie. 2011. Corpus Linguistics: Method, Theory and Practice Corpus Linguistics: Method, Theory and Practice.

[12] Michael Stubbs (1996) Text and Corpus Analysis: Computer-Assisted Studies of Language and Culture. Oxford: Blackwell.

[13] Nida, Eugena A. (1975). Language Structure and Translation. Stanford: Stanford University Press.

[14] Partington, Alan. (2004). Utterly content in each other's company. P:154. Semantic prosody and semantic preference. International Journal of Corpus Linguistics

[15] Partington, A. (2004). " Utterly content in each other's company" Semantic prosody and semantic preference. International journal of corpus linguistics.

[16] Schulte, R. (1999). Routledge Encyclopedia of Translation Studies. Translation Review. https://doi.org/10.1080/07374836.1999.10524085

[17] Stewart, D. (2009). Semantic prosody: A critical evaluation. In Semantic Prosody: A Critical Evaluation. https://doi.org/10.4324/9780203870075.

[18] Stubbs, Michael (2001). Words and Phrases: Corpus Studies of Lexical Semantics. Oxford: Blackwell.

[19] Stubbs, M. (2002). Two quantitative methods of studying phraseology in English. International Journal of Corpus Linguistics. 7 (2), 215-244.

[20] Sinclair, John. (1996). The search for units of meaning in Textus. English Studies in Italy, 9 (1996), pp. 75106

[21] Xiao, Richard and Tony McEnery. (2006). Collocation, semantic prosody, and near synonymy: A crosslinguistic perspective. Journal of Applied Linguistics. 27.1:103-129.

[22] Zhang, C. (2010). An Overview of Corpus-based Studies of Semantic Prosody. Asian Social Science. https://doi.org/10.5539/ass.v6n6p190

[23] Zhang, R. (2013). A Corpus-based Study of Semantic Prosody Change: The Case of the Adverbial Intensifier. Concentric: Studies in Linguistics. 